\title{
PENGARUH MODEL PEMBELAJARAN KOOPERATIF TIPE ROLE PLAYING BERBASIS PENDIDIKAN KARAKTER TERHADAP KOMPETENSI PENGETAHUAN IPS SISWA KELAS V SD NEGERI GUGUS KAPTEN KOMPYANG SUJANA DENPASAR BARAT
}

\author{
Ni Luh Sri Yuliani ${ }^{1}$, I Komang Ngurah Wiyasa ${ }^{2}$, Ni Nyoman Ganing ${ }^{3}$ \\ 1,2,3 Jurusan Pendidikan Guru Sekolah Dasar \\ Universitas Pendidikan Ganesha \\ Singaraja, Indonesia \\ email: sriyuliani150@yahoo.com ${ }^{1}, \mathrm{kmwiasa@gmail.com}^{2}$, \\ nyoman.ganing@gmail.com ${ }^{3}$
}

\begin{abstract}
Abstrak
Penelitian ini bertujuan untuk mengetahui pengaruh model pembelajaran kooperatif tipe role playing berbasis pendidikan karakter terhadap kompetensi pengetahuan IPS siswa kelas V SD Negeri Gugus Kapten Kompyang Sujana Denpasar Barat Tahun 2017/2018. Jenis penelitian ini adalah penelitian eksperimen semu dengan menggunakan desain penelitian nonequivalent control group design. Populasi penelitian ini adalah seluruh siswa kelas V SD Negeri Gugus Kapten Kompyang Sujana Denpasar Barat Tahun 2017/2018 sebanyak 637 siswa. Sampel penelitian ditentukan dengan teknik random sampling. Sampel dalam penelitian ini adalah kelas VC SD Negeri 9 Padangsambian sebagai kelompok eksperimen dan kelas VB SD Negeri 1 Padangsambian sebagai kelompok kontrol. Data kompetensi pengetahuan IPS diperoleh dengan instrumen berupa tes pilihan ganda biasa. Selanjutnya data dianalisis dengan uji-t. Hasil analisis menunjukkkan bahwa terdapat perbedaan yang signifikan kompetensi pengetahuan IPS antara kelompok siswa yang dibelajarkan mengggunakan model pembelajaraan kooperatif tipe role playing berbasis pendidikan karakter dan yang dibelajarkan menggunakan pembelajaran konvensional pada siswa kelas V SD Negeri Gugus Kapten Kompyang Sujana Denpasar Barat Tahun 2017/2018. Hal tersebut dibuktikan dengan hasil $t_{\text {hitung }} 9,079>t_{\text {tabel }}$ 2,000 pada taraf signifikansi $5 \%$ dengan $\mathrm{dk}=\mathrm{n} 1+\mathrm{n} 2-2=(43+43)-2=84$. Demikian pula nilai rata-rata kompetensi pengetahuan IPS siswa kelompok eksperimen $\bar{X}=82,00>\bar{X}=65,01$ rata-rata kompetensi pengetahuan IPS siswa kelompok kontrol. Dengan demikian dapat disimpulkan bahwa terdapat pengaruh model pembelajaran kooperatif tipe role playing berbasis pendidikan karakter terhadap kompetensi pengetahuan IPS siswa kelas V SD Negeri Gugus Kapten Kompyang Sujana Denpasar Barat Tahun 2017/2018.
\end{abstract}

Kata kunci: role playing, pendidikan karakter, kompetensi pengetahuan IPS

\section{Abstract}

This research aimed to determine the influence of cooperative learning model type role playing based on character education against the competency knowledge of social science students fifth graders in SD Negeri Gugus Kapten Kompyang Sujana Denpasar Barat in years 2017/2018. This research is an experimental research with the research design is quasi-exsperimental design (nonequivalent control group design). The population in this research is all fifth graders in SD Negeri Gugus Kapten Kompyang Sujana Denpasar Barat in years 2017/2018 as many as 637 students. Research sample is determined by random sampling technique. The sample in this research is grade VC SD Negeri 9 Padangsambian as experimental group and grade VB SD Negeri 1 Padangsambian as control group. Social science knowledge competence control data is collected with instruments in the form of multiple choice test. Then the data is analyzed by t-test. The result of the analysis shows that there is a significant difference of social science knowledge competence among group of students who are tought using cooperative learning model type role playing based on character education and conventional learning of fifth graders in SD Negeri Gugus Kapten Kompyang Sujana Denpasar Barat in years $2017 / 2018$. This is evidenced by the $T_{\text {count }}$ of $=9,079$ and $T_{\text {table }}=2,000$ at the significant level of $5 \%$ with $\mathrm{dk}=\mathrm{n} 1+\mathrm{n} 2-2(43+43-2=84)$. Similarly the average score of knowledge competence of social science students experimental group $\bar{X}=82,00>\bar{X}=65,01$ average of social science knowledge competence of control group students. Thus it can be concluded that the application of 
cooperative learning model type role playing based on character education influence the knowledge competence of social science fifth grade in SD Negeri Gugus Kapten Kompyang Sujana Denpasar Barat in years 2017/2018.

Keywords: role playing, character education, knowledge competence of social science

\section{Pendahuluan}

Pendidikan merupakan pondasi utama dalam mengelola, mencetak, dan meningkatkan sumber daya manusia yang handal dan berwawasan sehingga mampu untuk menjawab tantangan di masa mendatang. Pendidikan mempunyai peranan yang sangat besar dalam membentuk karakter peserta didik, yang seharusnya ditanamkan sejak dini. Salah satu usaha pemerintah untuk memperbaiki kualitas mutu pendidikan agar dapat mencetak manusia yang berkualitas adalah dengan memperbaiki kurikulum.

Pembelajaran pada kurikulum 2013 menekankan pada pendidikan karakter atau penumbuhan budi pekerti bagi peserta didik yang dikemas dalam pembelajaran tematik terpadu. Salah satu muatan materi dalam tematik terpadu yaitu IImu Pengetahuan Sosial (IPS). Dalam BSNP (2006:175) dinyatakan, Ilmu Pengetahuan Sosial (IPS) merupakan salah satu mata pelajaran yang diberikan mulai dari SD/ MI/ SDLB sampai SMP/ MTs/ SMPLB. IPS mengkaji seperangkat peristiwa, fakta, konsep, dan generalisasi yang berkaitan dengan isu sosial. Melalui mata pelajaran IPS, peserta didik diarahkan untuk dapat menjadi warga negara Indonesia yang demokratis, dan bertanggung jawab, serta warga dunia yang cinta damai. Pembelajaran IPS yang diberikan pada SD Negeri Gugus Kapten Kompyang Sujana Denpasar Barat menggunakan model pembelajaran konvensional.

Pembelajaran konvensional menerapkan pendekatan saintifik. Wartini (2014:2) menyatakan pendekatan saintifik adalah "pembelajaran yang mendorong anak untuk melakukan keterampilan- keterampilan ilmiah seperti mengamati, menanya, mengumpulkan informasi, mengasosiasi dan mengkomunikasikan."

Pembelajaran yang telah dilakukan oleh guru di SD Negeri Gugus Kapten Kompyang Sujana sudah berjalan dengan baik, namun dalam proses pembelajaran belum adanya penanaman nilai karakter, seperti siswa yang menunjukkan sikap kurang disiplin, dan bermain selama proses pembelajaran secara berkelompok sehingga membuat suasana pembelajaran di kelas menjadi tidak kondusif.

Teramati pula belum terintegrasikannya pendidikan karakter dengan muatan materi IPS, maka alangkah baiknya dalam pembelajaran diusahakan menggunakan pembelajaran yang sesuai dengan karakteristik siswa serta dapat mengemas pembelajaran dengan kreatif, menarik, menantang dan menyenangkan. Pemilihan model pembelajaran yang tepat pada akhirnya dapat memberikan kesempatan seluas-luasnya kepada peserta didik untuk dapat berkembang sesuai dengan keinginan dan potensi yang dimiliki.

Penggunaan model pembelajaran yang sesuai dapat membuat pembelajaran terasa menyenangkan serta kompetensi pengetahuan IPS yang akan dicapai nantinya benar-benar berguna bagi siswa. Salah satu model pembelajaran yang dapat digunakan adalah model pembelajaran kooperatif tipe role playing berbasis pendidikan karakter. Tastra (2013:3) menyatakan, model pembelajaran kooperatif adalah "strategi belajar dengan sejumlah siswa sebagai anggota kelompok kecil yang tingkat kemampuannya berbeda dan harus saling bekerjasama dan saling membantu untuk memahami materi pelajaran". Nurhasanah (2016:613) menyatakan model pembelajaran kooperatif tipe role playing yaitu "suatu model pembelajaran yang mengajak siswa untuk terlibat langsung dalam pembelajaran, penguasaan bahan pelajaran berdasarkan pada kreativitas serta ekspresi siswa dalam meluapkan imajinasi terkait dengan bahan pelajaran yang ia dalami tanpa adanya keterbatasan kata dan gerak, namun tidak keluar dari bahan ajar."

Menurut Kurniasih (2016:69) model pembelajaran role playing memiliki beberapa kelebihan diantaranya, yaitu "proses pembelajarannya melibatkan seluruh siswa untuk berpartisipasi, siswa mempunyai kesempatan untuk mewujudkan kemampuannya dalam 
bekerja sama, dapat berkesan dengan kuat dan tahan lama dalam ingatan siswa, sangat menarik sehingga membangkitkan kelas menjadi dinamis dan penuh antusias". Nurhasanah (2016:614) menyatakan "penggunaan model pembelajaran kooperatif tipe role playing dapat menjadikan siswa pribadi yang imajinatif, mempunyai minat luas, mandiri dalam berifikir, ingin tahu, penuh energi dan percaya diri serta siswa mampu meningkatkan kerjasamanya. Selain itu, siswa dapat melatih, memahami dan mengingat bahan materi yang akan disampaikan atau didramakan sesuai dengan gaya bahasa dan gaya belajar siswa. Hal ini dikarenakan siswa belajar melalui pengalaman langsung".

Huda (2016:209) menyatakan pelaksanaan pembelajaran dengan model pembelajaran kooperatif tipe role playing agar dapat berjalan dengan efektif, ada beberapa tahapan yang perlu dilakukan dalam merencanakan dan menyiapkan pembelajaran, yaitu: (1) guru menyusun/menyiapkan skenario yang akan ditampilkan (2) guru menunjuk beberapa siswa untuk mempelajari skenario dalam waktu beberapa hari sebelum pelaksanaan kegiatan belajar mengajar (3) guru membentuk kelompok siswa yang masingmasing beranggotakan 5 orang (4) guru memberikan penjelasan tentang kompetensi yang ingin dicapai, (5) guru memanggil beberapa siswa yang sudah ditunjuk untuk melakonkan skenario yang sudah dipersiapkan, (6) masing-masing siswa berada di kelompoknya sambil mengamati skenario yang sedang diperagakan, (7) setelah selesai ditampilkan masingmasing siswa diberikan lembar kerja untuk membahas/mem-beri penilaian atas penampilan masing-masing kelompok, (8) masing masing kelompok menyam-paikan hasil kesimpulannya, (9) guru memberikan kesimpulan dan evaluasi secara umum".

Penerapan model pembelajaran kooperatif tipe role playing ini dalam pelaksanaanya disertai dengan pendidikan karakter yang memunculkan nilai-nilai karakter dan budaya bangsa yaitu nilai religius, toleransi, kreatif, demokratis, rasa ingin tahu, peduli sosial dan tanggung jawab agar pembelajaran yang dilakukan bisa lebih optimal, bervariasi, dan bermakna.

Annur (2016:43) menyatakan, pendidikan karakter adalah "suatu sistem penanaman nilai-nilai cara berfikir dan berakhlak di dalam kehidupan sehari-hari yang bertujuan untuk membentuk pribadi anak agar mampu bekerja sama dengan seluruh komponen masyarakat." Nilai-nilai sosial perlu dijadikan materi dari pendidikan karakter dikarenakan akan menjadi pondasi penting bagi pembangunan bangsa. Nilai-nilai sosial memberikan pedoman bagi warga masyarakat dalam bertindak dan berperilaku. Dengan demikian, penelitian ini diusulkan dengan judul Pengaruh Model Pembelajaran Kooperatif Tipe Role Playing Berbasis Pendidikan Karakter terhadap Kompetensi Pengetahuan IPS Siswa Kelas V SD Negeri Gugus Kapten Kompyang Sujana Denpasar Barat Tahun 2017/2018.

\section{Metode}

Pelaksanaan penelitian dilakukan di SD Negeri Gugus Kapten Kompyang Sujana Denpasar Barat Tahun 2017/2018. Waktu penelitian terkait dengan penelitian ini dilaksanakan selama 2 bulan mulai April sampai dengan Mei 2018, perlakuan sebanyak 6 kali di kelompok eksperimen dan 6 kali di kelompok kontrol. Jumlah perlakuan yang diberikan telah disesuaikan dengan jam pelajaran terkait materi dalam penelitian ini yang telah diatur dalam kurikulum dan silabus.

Jenis penelitian yang diguna-kan adalah eksperimen semu (quasi experiment). Penelitian eksperimen semu ini membandingkan dua jenis model pembelajaran, model pembelajaran kooperatif tipe role playing berbasis pendidikan karakter dan pembelajaran konvensional, yang mana kedua model pembelajaran tersebut mempunyai pengaruh terhadap satu variabel terikat (kompetensi). Hal ini dikarenakan kemampuan peneliti dalam mengamati perilaku siswa sangat terbatas terutama ketika siswa berada di luar sekolah (rumah), peneliti juga tidak memiliki kemampuan untuk mengetahui persepsi siswa terhadap perlakuan secara pasti. Desain eksperimen yang digunakan adalah "nonequivalent control group design".

Pada desain ini kedua kelompok yang akan diteliti diberikan pre test dan post test. Pre test tidak dianalisis tetapi hanya digunakan untuk penyetaraan kelompok. Teknik yang 
digunakan dalam peyetaraan kelompok adalah dengan menggunakan teknik matching. Setelah itu peneliti memberikan perlakuan, yaitu dengan menerapkan model pembelajaran kooperatif tipe role playing berbasis pendidikan karakter kepada kelompok eksperimen, dan pembelajaran konvensional pada kelas kontrol.

Populasi adalah "keseluruhan dari objek, orang, peristiwa, atau sejenisnya yang menjadi perhatian dan kajian dalam penelitian" (Setyosari, 2015:221). Populasi penelitian ini adalah seluruh siswa kelas V SD Negeri Gugus Kapten Kompyang Sujana Denpasar Barat Tahun 2017/2018 yang berjumlah 637 siswa. Agung (2016:49) menyatakan sampel adalah "sebagian dari populasi yang diambil, yang dianggap mewakili seluruh populasi yang diambil dengan menggunakan teknik tertentu". Teknik pengambilan sampel pada penelitian ini dilakukan dengan cara teknik random sampling, karena dalam penelitian ini dipilih 2 kelas yang dijadikan subjek penelitian. Terdapat sebanyak 16 kelas $\mathrm{V}$ yang terdiri dari 7 Sekolah Dasar Negeri di Gugus Kapten Kompyang Sujana. Setelah mendapatkan 2 kelas yang diperoleh dari hasil random sampel kelompok, maka selanjutnya 2 kelas yang terpilih diberikan pre test. Pre test yang diberikan untuk menyetarakan kelompok. Penyetaraan kelompok dilakukan dengan teknik matching. Darmadi $(2014,234)$ menyatakan, matching adalah "suatu teknik untuk menyera-gamkan kelompok pada suatu varia-bel atau lebih yang oleh peneliti telah diitentifikasikan mempunyai hubungan yang erat dengan penampilan (performance) variabel tidak bebas." Setelah didapatkan pasangan dengan nilai yang sama maka 2 kelas tersebut dikatakan setara. Berdasarkan hasil penyetaraan yang telah dilakukan terdapat 43 pasang siswa yang memiliki nilai yang sama, yaitu 43 siswa dari Kelas V SD Negeri 9 Padangsambian dan 43 siswa dari kelas V SD Negeri 1 Padangsambian. Selanjutnya dilakukan pengundian untuk menentukan kelas kontrol dan kelas eksperimen. Sehingga populasi sampel yang digunakan dalam penelitian ini berjumlah 86 siswa, yaitu 43 siswa dari SD Negeri 9 Padangsambian sebagai kelompok eksperimen dengan diberi perlakuan berupa model pembelajaran kooperatif tipe role playing berbasis pendidikan karakter dan 43 siswa dari SD Negeri 1 Padangsambian sebagai kelompok kontrol dengan diberi perlakuan berupa pembelajaran konvensional.

Data yang dikumpulkan dalam penelitian ini adalah data kompetensi pengetahuan IPS

siswa kelas V SD Negeri Gugus Kapten Kompyang Sujana Denpasar Barat Tahun 2017/2018. Metode pengumpulan data yang digunakan pada penelitian ini adalah metode tes. Kegiatan pengumpulan data dilaksanakan pada siswa kelas V SD di Gugus Kapten Kompyang Sujana Denpasar Barat Tahun 2017/2018 yang menjadi anggota sampel. Data tentang kompetensi pengetahuan IPS dikumpulkan dengan tes kompetensi pengetahuan IPS. Menurut Arikunto (2012:67), tes merupakan "alat atau prosedur yang digunakan untuk mengetahui atau mengukur sesuatu dalam suasana, dengan cara dan aturan-aturan yang sudah ditentukan". Tes yang akan digunakan untuk mengukur kompetensi pengetahuan IPS berupa tes objektif dalam bentuk pilihan ganda biasa. Rancangan penelitian yang digunakan dalam penelitian ini adalah kuantitatif dengan menggunakan uji-t sebagai alat untuk menganalisis data. Deskripsi data hasil kompetensi pengetahuan IPS siswa yang dipaparkan meliputi nilai rata-rata, varians, dan standar deviasi.

\section{Hasil dan Pembahasan}

Pelaksanaan pembelajaran di dalam kelas selama ini secara umum telah berlangsung sesuai dengan rencana pelaksanaan pembelajaran yang telah disusun sebagai penerapan model pembelajaran kooperatif tipe role playing berbasis pendidikan karakter di kelas V SD Negeri 9 Padangsambian ditetapkan sebagai kelompok eksperimen yang diberi perlakuan sebanyak 6 kali pertemuan, selanjutnya diberikan post test untuk memeroleh hasil kompetensi pengetahuan IPS.

Nilai mean atau rata-rata kompetensi pengetahuan IPS siswa yang mengikuti pembelajaran menggunakan model pembelajaran kooperatif tipe role playing berbasis pendidikan karakter, yaitu $\bar{X}=82,00$ dengan varians 55,95 dan standar deviasi $(s=7,48)$, sedangkan nilai mean atau rata-rata kompetensi pengetahuan IPS siswa yang mengikuti 
pembelajaran konvensional, yaitu $\bar{X}=65,01$ dengan varians 94,68 dan standar deviasi (s= 9,73).

Perhitungan analisis data hasil penelitian yang diperoleh menunjukkan bahwa kompetensi pengetahuan IPS kelompok eksperimen yakni siswa yang mengikuti pembelajaran menggunakan model pembelajaran role playing berbasis pendidikan karakter memiliki nilai mean lebih tinggi dari pada kelompok kontrol yakni siswa yang mengikuti pembelajaran menggunakan pembelajaran konvensional yaitu $\bar{X}=82,00>\bar{X}=65,01$.

Sebelum menggunakan uji-t untuk menganalisis uji hipotesis, dilakukan terlebih dahulu uji prasyarat. Uji prasyarat tersebut Tabel 1. Elemental compositions of sampling sites meliputi uji normalitas dan uji homogenitas varians yang diuraikan berikut ini.

Uji normalitas dilakukan untuk mengetahui sebaran frekuensi skor, untuk menguji data kompetensi pengetahuan IPS kelompok eksperimen dan kontrol adalah rumus Chi Kuadrat. Kriteria pengujian pada uji normalitas adalah jika $x^{2}$ hitung $\leq x^{2}$ tabel maka sebaran data kedua kelompok berdistribusi normal. Berdasarkan hasil uji normalitas kelompok eksperimen, diperoleh Chi Kuadrat hitung $\left(\mathrm{x}^{2}\right.$ hitung $\left.=3,795\right)$ kemudian nilai tersebut dibandingkan dengan Chi Kuadrat tabel dengan taraf signifikan $5 \%$ dk $5\left(x_{\text {tabel }}^{2}=11,070\right)$. Hal ini menunjukkan bahwa $x_{\text {hitung }}^{2} \leq \mathrm{x}_{\text {tabel }}^{2}$ berarti data hasil kompetensi pengetahuan IPS kelompok eksperimen berdistribusi normal. Berdasarkan hasil uji normalitas kelompok kontrol, diperoleh Chi Kuadrat hitung $\left(x^{2}\right.$ hitung $\left.=9,951\right)$ kemudian nilai tersebut dibandingkan dengan Chi Kuadrat tabel $\left(x_{\text {tabel }}^{2}=11,070\right)$. Hal ini menunjukkan bahwa $x^{2}{ }_{\text {hitung }} \leq x^{2}$ tabel berarti data hasil kompetensi pengetahuan IPS kelompok kontrol berdistribusi normal.

Pengujian homogenitas varians antar kelompok dimaksudkan untuk meyakinkan bahwa perbedaan yang diperoleh uji-t benar-benar berasal dari perbedaan antar kelompok bukan disebabkan oleh perbedaan di dalam kelompok. Uji homogenitas varians yang dilakukan dalam penelitian ini menggunakan uji $F$. Dari hasil analisis, diperoleh $F_{\text {hitung }}=1,67$ dan $F_{\text {tabel }}=1,68$. Hal ini berarti $F_{\text {hitung }} \leq F_{\text {tabel, }}$, sehingga data kedua kelompok memiliki varians yang homogen. Berdasarkan hasil uji prasyarat yang terdiri dari uji normalitas dan uji homogenitas varians, disimpulkan bahwa data kedua kelompok sampel ialah berdistribusi normal dan memiliki varians yang homogen. Dengan demikian, uji hipotesis menggunakan uji-t dapat dilakukan.

Hipotesis yang diuji dalam penelitian ini adalah tidak terdapat perbedaan yang signifikan kompetensi pengetahuan IPS antara siswa yang dibelajarkan dengan model pembelajaran kooperatif tipe role playing berbasis pendidikan karakter dengan siswa yang dibelajarkan dengan model pembelajaran konvensional pada siswa kelas V SD Gugus Kapten Kompyang Sujana Denpasar Barat Tahun 2017/2018.

Hasil uji prasyarat yang meliputi uji normalitas dan homogenitas varians yang dilakukan dalam penelitian ini diperoleh kedua kelompok sampel berdistribusi normal dan memiliki varians yang homogen. Analisis statistik yang digunakan untuk menguji hipotesis penelitian ini adalah uji-t dengan separated varians. Berdasarkan hasil perhi-tungan uji-t, diperoleh $t_{\text {hitung }}=9,079$ dan untuk taraf signifikansi $5 \%$ dengan $\mathbf{d k}=(\mathbf{4 3 + 4 3 - 2})=84$ diperoleh $t_{\text {tabel }}=2,000$. Dengan demikian, nilai $t_{\text {hitung }}>t_{\text {tabel }}$ yakni 9,079 $>2,000$ sehingga $\mathrm{H}_{0}$ ditolak.

Perhitungan.rekapitulasi hasil analisis uji-t kelompok sampel penelitian ini disajikan dalam tabel 1 . berikut.

Tabel 1. Rekapitulasi Hasil Aanalisis Data Kompetensi Pengetahuan matematika Menggunakan Uji-t

\begin{tabular}{|c|c|c|c|c|c|c|c|c|}
\hline No & Sampel & $\mathrm{N}$ & Dk & $\bar{X}$ & $\mathrm{~S}^{2}$ & $t_{\text {hitung }}$ & $t_{\text {tabel }}$ & Status \\
\hline 1 & $\begin{array}{l}\text { Kelompok } \\
\text { eksperimen }\end{array}$ & 43 & \multirow{2}{*}{84} & 82,00 & 55,95 & \multirow{2}{*}{9,079} & \multirow{2}{*}{2,000} & \multirow{2}{*}{$\begin{array}{l}\mathrm{H}_{0} \\
\text { ditolak }\end{array}$} \\
\hline 2 & $\begin{array}{l}\text { Kelompok } \\
\text { kontrol }\end{array}$ & 43 & & 65,01 & 94,68 & & & \\
\hline
\end{tabular}


Berdasarkan uji hipotesis diperoleh $t_{\text {hitnung }}=9,079$ sedangkan pada taraf signifikansi $5 \%$ dan $\mathrm{dk}=84$ diperoleh nilai $t_{\text {tabel }}=2,000$ sehingga $t_{\text {hitnung }}=9,079>t_{\text {tabel }}=2,000$. Dengan demikian, hipotesis nol $\left(\mathrm{H}_{\mathrm{o}}\right)$ ditolak. Hal ini berarti terdapat perbedaan yang signifikan kompetensi pengetahuan IPS antara siswa yang dibelajarkan dengan model pembelajaran kooperatif tipe role playing berbasis pendidikan karakter dengan siswa yang dibelajarkan dengan model pembelajaran konvensional pada siswa kelas V SD Gugus Kapten Kompyang Sujana Denpasar Barat Tahun 2017/2018.

Perolehan hasil perhitungan analisis data yang dilakukan menunjukkan bahwa nilai rata-rata siswa yang dibelajarkan menggunakan model pembelajaran kooperatif tipe role playing berbasis pendidikan karakter $(\bar{X}=82,00)$ dengan perolehan nilai terendah 67 dan nilai tertinggi 97, sesuai dengan analisis nilai kompetensi pengetahuan IPS siswa pada kelompok eksperimen. Hasil rata-rata siswa yang dibelajarkan menggunakan pembelajaran konvensional ( $\bar{X}=65,01$ ) dengan perolehan nilai terendah 40 dan nilai tertinggi 77 , sesuai dengan analisis nilai kompetensi pengetahuan IPS siswa pada kelompok kontrol.

Hasil perolehan rata-rata kelompok eksperimen dan kelompok kontrol memiliki perbedaan sebesar 16,99. Dengan demikian, terdapat pengaruh model pembelajaran kooperatif tipe role playing berbasis pendidikan karakter terhadap kompetensi pengetahuan IPS siswa kelas V SD Negeri Gugus Kapten Kompyang Sujana Denpasar Barat tahun 2017/2018.

Berdasarkan hasil analisis data, dapat dinyatakan kedua kelompok sampel penelitian yang memiliki kemampuan setara, setelah diberikan perlakuan berupa pembelajaran dengan menggunakan model pembelajaran kooperatif tipe role playing berbasis pendidikan karakter dan yang menggunakan pembelajaran konvensional diperoleh hasil kompetensi pengetahuan IPS yang berbeda. Hal ini dapat dilihat juga dari $\bar{X}$ siswa yang mengikuti pembelajaran menggunakan model pembelajaran kooperatif tipe role playing berbasis pendidikan karakter lebih tinggi dibandingkan dengan $\bar{X}$ siswa yang mengikuti pembelajaran konvensional, dalam hal ini adalah pembelajaran yang hanya menggunakan pendekatan saintifik. Perbedaan hasil kompetensi pengetahuan dengan perolehan nilai ratarata yang lebih tinggi pada kelompok eksperimen dibandingkan kelompok kontrol disebabkan oleh perlakuan berupa model pembelajaran kooperatif tipe role playing berbasis pendidikan karakter dalam muatan materi IPS diberikan pada kelompok eksperimen.

Pada kelompok eksperimen, kegiatan pembelajaran dalam muatan materi IPS menggunakan model pembelajaran kooperatif tipe role playing berbasis pendidikan karakter berjalan dengan optimal dan kondusif. Hal ini disebabkan oleh pembelajaran dengan model kooperatif tipe role playing berbasis pendidikan karakter akan membuat siswa lebih aktif dalam pembelajaran serta lebih menarik karena siswa akan terlibat langsung dalam pembelajaran sekaligus dapat menumbuhkan minat belajar siswa dan dapat memunculkan nilai-nilai karakter budaya dan bangsa yaitu nilai religious, toleransi, kreatif, demokratis, rasa ingin tahu, peduli sosial, dan tanggung jawab.

Kurniasih menyatakan, model pembelajaran kooperatif tipe role playing dapat melibatkan seluruh siswa untuk berpartisipasi, mempunyai kesempatan untuk memajukan kemampuannya dalam bekerja sama, siswa bebas mengambil keputusan dan berekspresi secara utuh, dapat berkesan dengan kuat dan tahan lama dalam ingatan siswa. Sangat menarik bagi siswa, sehingga kelas menjadi dinamis dan penuh antusias, serta menumbuhkan rasa kebersamaan dan kesetiakawanan sosial yang tinggi. Berbeda pada kelompok kontrol, kegiatan pembelajaran konvensional yang hanya menggunakan pendekatan saintifik berjalan belum optimal. Hal ini disebabkan masih terdapat siswa yang kurang mampu mengaitkan antar materi pada muatan materi IPS dan kesulitan mengikuti setiap langkah pembelajaran yang perlu diberikan bimbingan lebih khusus. Pembelajaran menggunakan model pembelajaran kooperatif tipe role playing berbasis pendidikan karakter pada muatan materi IPS memberikan kesempatan yang lebih luas kepada siswa untuk mengonstruksikan pengetahuannya melalui berbagai kegiatan bermakna dan teratur yang tentunya menggembirakan bagi siswa pada setiap langkah pembelajarannya. Dengan demikian, perbedaan hasil kompetensi pengetahuan IPS dapat 
terlihat dari langkah pembelajaran yang dilakukan pada kedua kelompok tersebut, hasil analisis uji hipotesis, dan nilai rata-rata kelompok siswa yang mengikuti pembelajaran menggunakan model pembelajaran kooperatif tipe role playing berbasis pendidikan karakter dengan siswa yang mengikuti pembelajaran konvensional. Hasil temuan pada penelitian ini memiliki persamaan dengan penelitian sebelumnya yang relevan dan memperkuat hasil penelitian yang diperoleh. Hal tersebut didukung hasil penelitian yang diajukan oleh Martha (2014) yang menyatakan perbedaan signifikan hasil belajar IPS antara kelompok siswa yang mendapatkan treatment model pembelajaran kooperatif tipe role playing berbasis karakter berbantuan media audiovisual dengan kelompok siswa yang mendapatkan pembelajaran konvensional pada siswa kelas $\mathrm{V}$ semester 1 dan Windayani (2014) yang menyatakan terdapat perbedaan yang signifikan hasil belajar matematika kelompok siswa yang dibelajarkan menggunakan model pembelajaran kuantum bermuatan pendidikan karakter dan kelompok siswa yang dibelajarkan menggunakan pembelajaran konvensional.

Dengan demikian, pembelajaran menggunakan model pembelajaran kooperatif tipe role playing berbasis pendidikan karakter pada penelitian ini memiliki keunggulan yakni dapat menjadikan siswa pribadi yang imajinatif, mempunyai minat luas, mandiri dalam berifikir, ingin tahu, penuh energi dan percaya diri serta siswa mampu meningkatkan kerjasamanya. Selain itu, siswa dapat melatih, memahami dan mengingat bahan materi yang akan disampaikan atau didramakan sesuai dengan gaya bahasa dan gaya belajar siswa. Hal ini dikarenakan siswa belajar melalui pengalaman langsung. dapat memunculkan nilai-nilai karakter budaya dan bangsa yaitu nilai religius, toleransi, kreatif, demokratis, rasa ingin tahu, peduli sosial dan tanggung jawab

\section{Simpulan dan Saran}

Berdasarkan hasil analisis data kompetensi pengetahuan IPS pada kelompok eksperimen terdapat 43 siswa dengan nilai tertinggi yang diperoleh 97 dan nilai terendah adalah 67. Dari sebaran data tersebut diperoleh data rata-rata (mean) adalah 82,00 dan data yang paling sering muncul (modus) adalah 82,36 dan nilai tengah (median) yaitu 81,82 Berdasarkan PAP skala 5 rata-rata kelompok eksperimen termasuk kriteria baik.

Berdasarkan hasil analisis data kompetensi pengetahuan IPS pada kelompok kontrol terdapat 43 siswa dengan nilai tertinggi yang diperoleh 77 dan nilai terendah adalah 40. Dari sebaran data tersebut diperoleh data rata-rata (mean) adalah 65,01 dan data yang paling sering muncul (modus) adalah 76,44 dan nilai tengah (median) yaitu 67,36 Berdasarkan PAP skala 5 rata-rata kelompok kontrol termasuk kriteria cukup.

Dari hasil analisis diketahui bahwa sebaran data kompetensi pengetahuan IPS siswa berdistribusi normal dan memiliki varians yang homogen. Dari hasil analisis diperoleh $t_{\text {hitung }}=$ 9,079 dan $t_{\text {tabel }}=2,000$ pada taraf signifikansi $5 \%$ dengan $d k=84$. Oleh karena $t_{\text {hitung }} 9,079>$ $t_{\text {tabel }} 2,000$ maka $\mathrm{H}_{0}$ yang menyatakan tidak terdapat perbedaan yang signifikan kompetensi pengetahuan IPS kelompok siswa yang dibelajarkan melalui model pembelajaran kooperatif tipe role playing berbasis pendidikan karakter dengan kelompok siswa yang dibelajarkan melalui pembelajaran konvesional pada kelas V SD Negeri Gugus Kapten Kompyang Sujana Tahun 2017/2018 di tolak. Jadi dapat disimpulkan bahwa terdapat pengaruh model pembelajaran kooperatif tipe role playing berbasis pendidikan karakter terhadap kompetensi pengetahuan IPS siswa kelas V SD Negeri Gugus Kapten Kompyang Sujana Denpasar Barat tahun 2017/2018.

Berdasarkan pada simpulan penelitian yang diperoleh, maka beberapa saran dapat diajukan kepada beberapa pihak adalah sebagai berikut.

Kepada guru disarankan agar lebih kreatif untuk memberikan fasilitas berupa sumber belajar dan kesempatan yang lebih besar bagi siswa pada pembelajaran dengan menggunakan model pembelajaran kooperatif tipe role playing berbasis pendidikan karakter dan dapat dijadikan alternatif dalam proses pembelajaran untuk membantu peserta didik meningkatkan kompetensi pengetahuan IPS dengan maksimal.

Kepada kepala sekolah diupayakan agar dapat menggunakan hasil penelitian ini sebagai sebagai alternatif dalam mengelola pembelajaran agar sesuai dengan karakteristik 
pembelajaran IPS, sehingga mampu meningkatkan pengetahuan dan pemahaman peserta didik tentang IPS.

Kepada peneliti lain hendaknya hasil penelitian ini digunakan sebagai suatu acuan bagi peneliti lain untuk mengembangkan kemampuan diri dalam mempersiapkan diri sebagai calon pendidik dan meningkatkan pemahaman mengenai kurikulum 2013 dengan penerapan model pembelajaran kooperatif tipe role playing berbasis pendidikan karakter.

\section{Daftar Pustaka}

Agung, A.A Gede. 2016. Statistik Dasar Untuk Pendidikan. Yogyakarta: Depublish.

Annur, Fauzi. 2016. "Pendidikan Karakter Berbasis Keagamaan (Studi Kasus di SDTT Nur Hidayah Surakarta)" Jurnal Pendidikan dan Pengajaran. Volume 01 Nomor 01 (hlm 39-56).

Arikunto, Suharsimi. 2012. Dasar-dasar Evaluasi Pendidikan. Jakarta: PT Bumi Aksara.

BSNP. 2006. Standar Isi untuk Satuan Pendidikan Dasar dan Menengah. Jakarta: Badan Standar Pendidikan Nasional.

Darmadi, Hamid. 2014. Metode Penelitian Pendidikan dan Sosial. Bandung: Alfabeta.

Huda, Miftahul. 2015. Model Model Pengajaran dan Pembelajaran. Yogyakarta: Pustaka Belajar.

Kurniasih, Imas dan Berlin Sani. 2015. Ragam Pengembangan Model Pembelajaran. Kata Pena CV Solusi Distribusi.

Nurhasanah, Ismawati Alidha. 2016. "Penerapan Metode Role Playing Untuk Meningkatkan Hasil Belajar Siswa Pada Materi Hubungan Makhluk Hidup Dengan Lingkungannya". Jurnal Pena IImiah. Volume 1 Nomor 1, (hlm. 611-620).

Setyosari, Punaji. 2015. Metode Penelitian Pendidikan dan Pengembangan. Jakarta: Kencana Prenada Media Group.

Wartini, Ida Ayu Km Mirah. 2014. "Pengaruh Implementasi Pendekatan Saintifik Terhadap Sikap Sosial dan Hasil Belajar PKn di Kelas VI SD Jemabatan Budaya, Kuta". Jurnal Pendidikan dan Pengajaran. Volume 4, (hlm.1-11). 